\title{
Desafios para a Adesão ao TARV na Perspectiva dos Profissionais do Sistema de Saúde de Moçambique
}

\author{
Larissa Polejack ${ }^{1, *}$ (D), Ana Cláudia Almeida Machado ${ }^{1}$ (D, Carine de Souza Santos ${ }^{1}$ (D), \\ $\&$ Augusto Joaquim Guambe ${ }^{2}$ (D) \\ ${ }^{1}$ Universidade de Brasília, Brasília, DF, Brasil \\ ${ }^{2}$ Universidade Eduardo Mondlane, Maputo, Moçambique
}

\begin{abstract}
RESUMO - O objetivo do estudo foi compreender quais são os principais desafios para adesão ao tratamento antirretroviral em Moçambique na perspectiva dos profissionais de saúde que lidam com a temática do HIV/aids no país. O estudo é qualitativo, observacional e exploratório. Entrevistas semiestruturadas foram realizadas com 11 profissionais de saúde que prestam assistência em HIV/aids em sete das onze províncias do país. Os dados foram analisados por meio da técnica de análise do Discurso do Sujeito Coletivo. Os resultados foram categorizados em nove ideias centrais. Dentre os problemas mencionados pelos profissionais estão aspectos relacionados à cultura local, ao receio da revelação forçada do diagnóstico de HIV positivo a terceiros, à ausência de uma adequada compreensão sobre os benefícios do tratamento, à forma de organização dos serviços de saúde, a questões de gênero, a aspectos sociais como fome, dificuldades financeiras e problemas com transporte, dentre outros.
\end{abstract}

PALAVRAS-CHAVE: adesão ao tratamento, HIV/aids, profissionais de saúde, Moçambique

\section{Challenges for Adherence to Antiretroviral Treatment from the Perspective of Health System Professionals in Mozambique}

\begin{abstract}
The goal of the study was to understand the main challenges for adherence to antiretroviral treatment in Mozambique from the perspective of health professionals who deal with HIV/AIDS. The study is qualitative, observational, and exploratory. Semi-structured interviews were conducted with 11 health professionals who provide HIV/AIDS assistance in seven of the country's eleven provinces. Data analysis was based on the Discourse of the Collective Subject. Results were categorized into nine central ideas. Among the problems mentioned by health professionals there are aspects related to culture, the fear of forced disclosure of HIV positive diagnosis, the absence of an adequate understanding of the benefits of treatment, the way health services are organized, gender issues, and social aspects such as hunger, financial difficulties and problems with transportation, among others.
\end{abstract}

KEYWORDS: treatment adherence, HIV/AIDS, health professionals, Mozambique

A Síndrome da Imunodeficiência Adquirida (aids) causada por meio da infecção do vírus da imunodeficiência humana (HIV) surgiu na década de 1980 e tornou-se um problema de saúde da população mundial. Segundo dados Programa Conjunto das Nações Unidas sobre HIV/aids (UNAIDS) estima-se que 74,9 milhões [58,3 milhões-98,1 milhões] de pessoas foram infectadas no mundo pelo HIV desde o início da epidemia até o fim do ano 2018, dentre as quais 37,9 milhões [32,7 milhões - 44,0 milhões] estavam vivendo com HIV e aproximadamente 24,5 milhões [21,6 milhões-25,5 milhões] tinham acesso à terapia antirretroviral. No mundo, o número anual de mortes de pessoas de todas as idades por doenças relacionadas à aids caiu de um pico de 1,7 milhão [1,3 milhão a 2,4 milhões] em 2004 para 770000 [570 000-1 100 000] em 2018. Deve-se este declínio global de mortes à ampliação de oferta de

\footnotetext{
*E-mail: larissapolejack@hotmail.com

- Submetido: 10/10/2019; Revisado: 03/01/2020; Aceito: 14/06/2020.
} 
tratamento na África Oriental e Austral, região que abriga $54 \%$ da população de pessoas do mundo vivendo com HIV (UNAIDS, 2019a), onde se localiza Moçambique, local de realização do estudo.

Tal situação se configura como um problema de saúde pública (Polejack \& Seidl, 2010), considerando suas consequências sobre o processo de governabilidade e sustentabilidade das nações e sociedades. As altas taxas de mortalidade e morbidade do início da epidemia sofreram um declínio expressivo após a introdução do tratamento antirretroviral (TARV). A aids passou a ser considerada uma doença crônica, já que as pessoas vivendo com o HIV ganharam maiores possibilidades de manter boa qualidade de vida com a ampliação do acesso ao TARV (Polejack \& Seidl, 2010).

Moçambique, objeto de estudo do presente trabalho, localiza-se na região sul da África subsaariana, onde a epidemia de aids é generalizada (Fedatto, 2017). Ocupa o sexto lugar no núnero de incidências entre adultos no mundo. O problema é marcadamente grave em países em desenvolvimento, já que possuem menos recursos para oferecer serviços de saúde de qualidade e acesso universal aos cuidados em saúde para suas populações (Vieira et al., 2014).

Atualmente, a maioria dos países adota a estratégia Testar e Tratar (ou test and treat), que defende o início do tratamento logo após o diagnóstico positivo para o HIV (OMS, 2016). De acordo com Baggaley e Hollingsworth (2020), o tratamento como prevenção - não apenas de doenças relacionadas ao HIV, mas também de transmissão do vírus - foi proposto em 2006 como um meio de acabar com a epidemia por meio da realização de várias pesquisas que apresentaram evidências de que o tratamento precoce da maioria das pessoas que vivem com HIV (PVHS) poderia reduzir as taxas de transmissão do HIV para quase zero, no nível da população. Dessa forma, o tratamento como prevenção evoluiu para a abordagem universal de teste e tratamento de HIV (UTT), o que implicou na oferta de aconselhamento e testagem de HIV a toda população, além de disponibilização do TARV a todas as PVHS.

O UNAIDS anunciou novas metas ambiciosas para "acabar com a Aids até 2030", atingindo as metas 90-90-90 em 2020, o que significa um plano que atinja $90 \%$ das PVHS conhecendo seu status, $90 \%$ de cobertura antirretroviral (ART) entre aqueles que conhecem seu status e $90 \%$ de supressão viral (carga viral indetectável) entre pessoas em ART. Recentemente, essa meta foi atualizada: espera-se para o ano 2030 que: $95 \%$ dos PVHS tenham realizado o teste e 95\% dessas pessoas estejam em tratamento, alcançando 95\% de supressão viral (UNAIDS, 2014). Para que essas metas ambiciosas tenham êxito, é fundamental que se compreenda e que se invista maciçamente em estratégias de adesão aos cuidados e ao tratamento.

A adesão é um dos maiores desafios para a eficácia do tratamento para HIV/aids, uma vez que demanda a existência de um processo colaborativo entre a equipe de saúde e o paciente, num reconhecimento de seu protagonismo e papel ativo nas decisões sobre a terapia a ser adotada em seu tratamento (Brasil, 2008). O momento do recebimento do diagnóstico é crucial e pode trazer importantes consequências para a vida do paciente, para o tratamento e, por conseguinte, também para a adesão (Coutinho et al., 2018).

A adesão no contexto de saúde manifesta-se, dentre outros, por mudanças no comportamento e inclusão na rotina de práticas de auto-cuidado, tais como: práticas de atividade física, busca por uma alimentação saudável, não fumar, fazer uso da medicação tal como prescrito, e buscar preservar horas de descanso e lazer (Polejack, 2007). A baixa adesão também é influenciada pela falta de conhecimento e escassez de informações sobre os medicamentos em uso (Souza et al., 2019).

Aspectos positivos estão associados ao tratamento antirretroviral, como por exemplo, a desconstrução da ideia de morte e a construção de melhores perspectivas de vida (Costa et al., 2019). A experiência inicial da pessoa vivendo com HIV desde o momento da revelação do diagnóstico pode impactar positiva ou negativamente sua adesão ao tratamento, incluindo o processo individual de aceitação do resultado reagente ao teste anti-HIV e da própria soropositividade.

A adesão ao tratamento para a infeção inclui, ainda, lidar com preconceitos, inseguranças, entender a complexidade envolvendo o diagnóstico e o uso e efeitos dos medicamentos. Do mesmo modo, será necessário à pessoa vivendo com HIV conciliar essas questões a aspectos sociais, sexuais, e emocionais. Ainda, podem ser mencionados como aspectos que influenciam a adesão fatores ligados ao sujeito, à doença, ao tratamento, e aos fatores interpessoais (Brambatti \& Carvalho, 2005).

Os fatores ligados ao sujeito incluem suas atitudes frente ao diagnóstico e tratamento, seus conhecimentos, crenças, o suporte social percebido, aspectos socioeconômicos (renda, habitação, acesso a serviço de saúde) e condições clínicas do paciente. Já os fatores relacionados com a doença dizem respeito à sua gravidade, duração, ocorrência de outras doenças associadas à soropositividade, além da percepção de que o tratamento não tem alcançado resultados concretos. Por sua vez, os fatores ligados ao tratamento referem-se à complexidade do esquema terapêutico, sua duração, e outras características do tratamento. Dentre os fatores interpessoais, está a qualidade da relação entre a equipe de saúde e o usuário. Vale ressaltar que outros aspectos, tais como o preconceito e a estigmatização em torno da soropositividade também interferem fortemente na adesão. Ademais, aspectos relacionados com a organização dos serviços de saúde, tais como tempo de espera, ambiente pouco agradável, falta de acesso a exames complementares, e pouca possibilidade de diálogo com a equipe também são fatores decisiovos para uma boa adesão (Brambatti \& Carvalho, 2005). 
O contexto social e as questões culturais também influenciam a qualidade do tratamento. Aspectos sociais tais como a desigualdade gênero, estigmatização e discriminação são barreiras importantes para o acesso à saúde e podem interferir na forma como cada sujeito vai lidar com seu cuidado. Por exemplo, em Moçambique as mulheres que vivem com HIV comumente são vítimas de julgamento moral e são culpabilizadas pela doença, o que reforça o estigma, que por sua vez gera exclusão social, e, consequentemente, não-adesão. Tão importante quanto o acesso ao tratamento é a criação de medidas de combate aos estigma e discriminação, por meio do reconhecimento das questões culturais como aspecto central no processo de cuidado em saúde (Andrade \& Iriart, 2015).

Para entender a adesão como um processo biopsicossocial, é necessário reportar ao conceito ampliado de saúde, que estabalece que a saúde é um processo multifatorial influenciada por determinantes sociais. A partir desse processo, a produção de saúde e doença é fortemente influenciada pelas dimensões socioeconômicas e políticas vivenciadas pelas coletividades (Fonseca \& Corbo, 2007).

Problemáticas oriundas da área de saúde coletiva, como a pandemia de HIV, põem em choque a organização socioeconômica e cultural de um país. Torna-se necessária a elaboração de políticas públicas que considerem as múltiplas vivências presentes em dado contexto populacional, em prol de uma efetiva promoção de saúde, ampliação de acesso ao tratamento, e melhoria da qualidade de vida da população (Polejack, 2007). A pandemia da COVID-19 trará problemas socioeconômicos adicionais aos que já eram enfrentados por Moçambique, uma vez que a economia formal nacional já demonstrava fortes sinais de desaquecimento antes da crise sanitária mundial (Monié, 2020). Medidas tempestivas para conter o impacto da pandemia na epidemia deverão ser empregadas, já que é conhecida a relação inversa existente entre níveis de infecção pelo HIV e aspectos socioeconômicos da população, como renda (Medeiros et al., 2017; Mitano et al., 2016).

Segundo o Inquérito de Indicadores de Imunização, Malária e HIV/SIDA (IMASIDA), que é o mais recente documento oficial publicado pelo Ministério da Saúde a respeito da prevalência de HIV em Moçambique, a taxa de infecção da população de 15-49 anos é de 13,2\%, (15,4\% nas mulheres e $10,1 \%$ nos homens). Diferenças expressivas por províncias foram registradas, sendo a menor prevalência encontrada em Tete $(5,2 \%)$ e as maiores em Gaza $(24,4 \%)$ e Maputo Província (22,9\%). Em 2009, a prevalência era de $11,5 \%$ (MISAU, 2015b).

Segundo a UNAIDS, a redução mais expressiva no número de novas infecções no mundo pelo HIV de 2010 a 2018 ocorreu na Região leste e sul da África, onde, atualmente, residem 54\% das pessoas vivendo com HIV/ aids no mundo. A diminuição em $28 \%$ no número de novos casos se deve aos progressos que vêm ocorrendo no campo da prevenção, sobretudo no tocante ao uso de preservativos nas relações sexuais. Em que pese ter havido uma redução no número de mortes da ordem de $44 \%$ no período, é necessário destacar que o número de vidas afetadas pela infecção, assim como a quantidade de novos casos na região, ainda é alarmante (UNAIDS, 2019b).

Ressalta-se, outrossim, que em três regiões do mundo (Ásia Central; Oriente Médio e Norte da África; e América Latina), apesar dos esforços para conter a infecção pelo HIV, houve elevação do número de infecções anuais pelo vírus (UNAIDS, 2019b), demonstrando que, apesar de imensos avanços no campo do tratamento, o HIV continua sendo um desafio para vários países. Tendo isso em vista, é necessário que a produção científica considere as especificidades e necessidades dos governos e populações dessa parte do globo, de forma a fortalecer atores locais e instrumentalizar a elaboração de políticas públicas capazes de minimizar os problemas presentes no combate à epidemia e, especialmente na melhoria da adesão.

Ameaças ao acesso universal e gratuito ao TARV por parte de PVHA no Brasil tornaram-se fontes de preocupação recente no país, tendo em vista a possibilidade do "vírus ideológico" vir a suplantar o vírus biológico. Políticas de austeridade nesse campo, discursos obscurantistas e a oposição à ciência por parte dos formuladores de políticas públicas podem, inclusive, acentuar ainda mais o quadro de estigma e discriminação que sofrem as PVHA (Agostini et al., 2019), o que, por sua vez, pode impactar a adesão ao tratamento recomendado.

Do ponto de vista da relevância científica, é importante considerar que a boa adesão é um requisto essencial para a efetividade do tratamento antirretroviral e a falha no tratamento pode trazer sérias consequencias, não apenas para a saúde do indíviduo, mas também pode impactar na saúde pública, por meio da transmissão de cepas virais mais resistentes, assim como pode ter um impacto econômico importante, considerando que os medicamentos de segunda linha geralmente são mais caros que os de primeira linha (Chesney et al., 2000).

Este artigo é um recorte de um estudo de relevante amplitude nacional entitulado "Estudos sobre estratégias de apoio à adesão ao tratamento anirretroviral no âmbito comunitário", aprovado pelo Comitê Nacional de Bioética para a Saúde de Moçambique, sob número 46/CNBS/2017, com o intuito de compreender quais são os principais desafios para adesão ao tratamento antirretroviral em Moçambique na perspectiva dos profissionais de saúde, dos usuários e dos gestores que lidam com a temática do HIV/aids realizado em sete províncias moçambicanas. O objetivo deste artigo é compartilhar os resultados encontrados junto ao grupo dos trabalhadores da saúde no que se refere aos desafios por eles apontados relativos à adesão ao TARV no país. 


\section{MÉTODO}

O estudo é qualitativo, observacional, de natureza exploratória, com amostragem definida por conveniência. As entrevistas semiestruturadas foram realizadas com onze profissionais de saúde que prestam assistência em HIV/aids em sete das onze províncias de Moçambique.

Os participantes atuavam nas províncias de Nampula (Região Norte), Sofala, Manica, Zambézia (Região Centro), Maputo Cidade, Maputo Província e Gaza (Região Sul). Os dados foram agrupados considerando-se as três regiões geográficas do país para facilitar a síntese de informações e, em especial, de modo que os resultados possam auxiliar gestores locais que atuam regionalmente na tomada de decisões. Participaram profissionais que atuam nas unidades de saúde que lidam com a temática de HIV/aids, homens e mulheres com idades entre 18 e 60 anos, que consentiram voluntariamente com a participação no estudo após leitura do Termo de Consentimento.

Como os locais de realização das entrevistas foram as unidades de saúde onde os entrevistados exercem sua atividade de trabalho, optou-se por conduzi-las com a presença do pesquisador in loco, o que trouxe uma vantagem adicional à equipe de pesquisa, que foi a possibilidade de conhecer o local onde são realizados os atendimentos aos pacientes. Além de uma maior familiaridade dos pesquisadores com o contexto local, houve também benefício para o estabelecimento de rapport entre a equipe de pesquisadores e os profissionais entrevistados. O objetivo principal das entrevistas foi comprender quais os principais desafios relacionados à adesão à TARV das pessoas vivendo com HIV na perspectiva dos profissionais de saúde.

A análise de dados foi realizada por meio da técnica de análise do Discurso do Sujeito Coletivo (DSC), cujo método consiste em analisar o material verbal coletado por meio de perguntas abertas, a partir de um conjunto de indivíduos representativos de uma coletividade, a fim de produzir discursos a partir da expressão livre dos sujeitos. Tendo isso em vista, será privilegiado o uso das expressões verbais reais do sujeito, uma vez que não é facultado ao pesquisador tecer ajustes nos conteúdos das falas dos participantes, visando ao respeito e à fidelidade ao discurso tal como foi proferido (Lefèvre \& Lefèvre, 2005). Além disso, as expressões usadas pelos participantes foram mantidas com respeito ao português falado no contexto moçambicano - apesar de algumas serem diferentes das que são comumente utilizadas no português falado no Brasil, acredita-se que não houve perda na compreensão do conteúdo.

Segundo os preceitos da técnica do DSC, Expressõeschave $(\mathrm{ECH})$ são pedaços, trechos ou transcrições literais do discurso que são identificadas pelo pesquisador, que revelam a essência do depoimento, ou o conteúdo central da pesquisa. As Ideias Centrais (IC) sintetizam o sentido dos discursos analisados em cada conjunto de expressões-chave. Pelo fato de não possuírem caráter interpretativo, apenas descrevem o sentido do depoimento, ou do conjunto de depoimentos. Já as Ancoragens referem-se à manifestação linguística explícita de uma dada teoria, ideologia ou crença que o autor do discurso professa, a qual, na qualidade de afirmação genérica, é usada pelo participante para enquadrar uma situação específica. Por fim, o DSC é um discurso síntese, redigido na primeira pessoa do singular, composto pelas expressões-chave que possuem a mesma ideia central ou ancoragens (Lefèvre \& Lefèvre, 2005).

Os autores ainda ressaltam que a diferença básica entre ideia central e ancoragem é que, na primeira, as EC remetem a um sentido mais direto, enquanto a segunda representa a teoria, ideologia ou crença subjacente. As IC estão sempre presentes nos depoimentos, entretanto, as ancoragens só são consideradas quando estiverem concretas e explicitamente presentes nesses depoimentos, o que nem sempre acontece (Lefèvre \& Lefèvre, 2005). Tal abordagem parte do pressuposto de que o pensamento de uma coletividade sobre um tema pode ser visto como o conjunto de discursos ou representações sociais. Essa abordagem permite o estabelecimento de um diálogo com o social a partir do olhar do sujeito.

Assim, a partir dos discursos produzidos pelos onze participantes da pesquisa, buscou-se extrair as IC e/ou ancoragens e as correspondentes EC de cada entrevista. A partir das EC das IC ou ancoragens semelhantes, compuseram-se os discursos-síntese, na primeira pessoa do singular, representativo da coletividade, para que, em seguida, esse discurso coletivo pudesse ser discutido pela equipe de pesquisa até sua elaboração final.

\section{RESULTADOS}

Da análise do discurso dos profissionais de saúde sobre os principais desafios ou barreiras para a adesão ao TARV, emergiram nove IC, as quais serão apresentadas a seguir. A questão nortadora foi: "Quais as dificuldades ou barreiras enfrentadas na adesão ao tratamento?".

IC 1 - Por conta do medo da reação dos próprias ARVs as pessoas acabam desistindo
DSC1: Desafios sempre existem, primeiro por se tratar de uma doença para longa vida, e os comprimidos também levam muito tempo, e ainda temos o problema dos efeitos colaterais. Com isso tem que mudar os seus hábitos. Há pacientes que quando estão em casa não tomam a medicação. Logo nos primeiros dois meses em que o paciente inicia a toma dos medicamentos, por causa das 
reações diz que está a faltar por que levou o comprimido e quando chegou em casa estava a fazer mal "ih, eu não ei de tomar mais porque depois de tomar não levantei ainda" ou "levantei muito cansado". Outros reclamam de vertigem, que vomitam, de fraqueza e a maioria dos doentes reclamam a questão de fome né "depois que eu tomei os comprimidos são muitos e me mordem a barriga, fome”. Então, por conta do medo da reação das próprias ARV's as pessoas acabam desistindo.

IC 2 - Cuidar desse hospital não é tarefa fácil

DSC2: Essa unidade sanitária tem um problema sério de pessoal, como falta de técnicos e clínicos para atendimento com pessoas vivendo com HIV. Cuidar desse hospital não é tarefa fácil, enche muito e eles acabam reclamando por causa da demora. Os clínicos que são poucos, sempre foram, e os pacientes são muitos. Então quando temos um déficit de clínico já fica tudo muito complicado. Outro constrangimento é o instrumento de avaliação psicossocial, pois são muitos livros e às vezes com páginas diferentes, são curtinhos. Estamos a receber livros com sessenta páginas e logo temos que mudar para outro. Então, se eu já listei o paciente no livro um e estou no quinze, o paciente que estava no livro um acaba esquecido. O próprio sistema em que trabalhamos não permite que as informações que estão a ser facultadas sejam super confidenciadas, pois não temos espaços. Há problemas de gabinetes onde geralmente as consultas que deveriam ser integradas, não são. Pois as US não têm essas infraestruturas. Aqui os serviços TARV e APSS fazemos no mesmo gabinete porque nós aqui não temos psicólogo, é tudo no mesmo sitio. Em algum momento acaba eu sentindo que não consigo fazer chegar aquela informação devido à pressão do próprio trabalho porque eu trabalho sozinho. Então olhando pra isso ai tenho doentes que não tem nada a ver com o HIV/SIDA, mas tem aquele que tem a ver e eu tenho que atender as duas partes. $O$ aconselhamento não se faz em 10 minutos ou em 5 minutos. Hoje, o que leva a pessoas a desistir, a não seguir, é o caso mesmo de sensibilização e do atendimento.

IC 3 - O paciente não volta

DSC3: Depois do primeiro aconselhamento da APSS, mesmo assim o paciente não volta. Tem um problema que a maior parte de paciente que sai alugam as casas, mudam de um dia para outro e acabam não dando satisfação. Inicia como tratamento, depois de 2, 3 dias ou uma semana, não aparece. Muitas perdas que também costumamos ter são aqueles casos de pacientes que já testaram noutros distritos e estavam em seguimento, ejá está aqui e quer testar de novo. Quando vê que o resultado é o mesmo, abre o processo, leva aquele medicamento e não volta mais. E quando começamos a procurar, é dificil de localizar, primeiro de entrar em contato, depois é o bairro, quarteirão, ou secretário que está registrado na zona não é conhecido, pois há certos pacientes que dão endereços e números errados e não conseguimos ligar.
IC 4 - Não querer revelar o diagnóstico aos parceiros e aos familiares

DSC4: Um dos maiores desafios que temos é em relação a questão de certas discordâncias, pois quando se fala em discordância acho que o problema maior é na cidade que em zonas rurais, talvez porque depende muito mais do outro. Algumas mulheres dizem "eu não posso tomar porque o meu marido não me autorizou”, "e se eu for expulsa do lar, como vou ficar?", então tem essa parte de não querer revelar o diagnóstico ao parceiro e aos familiares. O paciente pode ter vontade, mas se não tiver apoio social este é um problema grande, pois para ter apoio a primeira coisa é revelar seu estado. Esse é um grande desafio, pois uma vez não revelada a sua situação, dificilmente vai sentir à vontade sempre tendo que sair de casa para o hospital. Só tomam os medicamentos no dia em que a esposa, os filhos, irmãos não estiverem em casa. Então ele não adere o tratamento como deve ser.

IC 5 - Estamos a perder pacientes por causa das questões financeiras

DSC5: Algumas das vezes estamos a perder pacientes por causa da falta de recursos, questões financeiras. Temos o problema da falta de meios de transporte, pois temos pacientes que vivem distantes da US e não é possível que saiam todo dia para levar o medicamento, então só vem mesmo quando estiver muito doente, quando não estiver a aguentar. Alguns pacientes caminham para chegar até aqui, mas se não tem condições de vim, não vem. Também temos alguns pacientes sem condições que acabam se queixando que é um cadinho complicado tomar o medicamento sem ter o que comer, e o programa nutricional que temos aqui não é muito abrangente.

IC 6 - Por causa da demora ficam frustrados

DSC6: Por causa da demora do tempo ficam frustrados, porque são doentes que querem um atendimento especial, então, logo querem entrar, prescrever a receita e ir para casa. Então é um dos grandes constrangimentos o paciente vim mais cedo e começar a ser atendido mais tarde. Por termos só um clínico, eles ficam muito tempo lá, então é muito complicado. Pois o clínico tem que atender aqueles que chegaram de manhã. Muitas das vezes o tempo de espera é tão elevado que ele acaba desistindo. Passa mais ou menos por uns cinco ou seis gabinetes. Os sistemas fazem com que o paciente se sinta menos aderente e acaba abandonando.

IC 7 - Tem a questão da discriminação

DSC7: Tem a questão do próprio sigilo nos distritos, pois são vilas pequenas em que a informação se espalha facilmente. Muitas vezes tem a questão da discriminação, dizem "não, tenho medo de discriminação, ser separado”. Então, para alguns ainda é um tabu, uma coisa que "epa, não quero ser visto”. Não querem fazer perto da sua casa para não serem vistos, pois ainda existe discriminação mesmo na própria casa do paciente. Alguns vivem longe, mas todos que vem 
também tem serviços lá, mas tem outros que preferem vir tratar aqui. Então há pacientes que têm condições e fazem tratamento nessa unidade sanitária, mas porque "Eu tenho condições, sou uma personalidade, sou Fulana e não quero que aqui eles me vejam”. Então não sei se vão aderir porque vão ter vergonha, medo de discriminação e estigmatização.

IC 8 - Há aqueles que recorrem ao tratamento tradicional

DSC8: Há pessoas que não acreditam que teve problema de tuberculose por causa de HIV, porque ele tem diminuição de imunidade, existem questões tradicionais. Aqui fazem as pessoas desacreditarem da tuberculose por alguma questão, e uma delas é de que está relacionada a tradição de alguém foi dado na bebida ou porque foi dado na comida. Ai as pessoas põem na cabeça que realmente a tuberculose vem dessas situações. Há aqueles que recorrem ao tratamento tradicional e muitas vezes não dá nada de positivo, e quando pensam em ir ao hospital já estão numa fase avançada. Então muitas vezes, é por essa razão que as mortalidades são muito elevadas, porque as pessoas não vão diretamente ao hospital.

IC 9 - Falta um pouco de informação

DSC9: O hospital está em um lugar fraco com a comunidade, porque antes nós tínhamos uns grupos aqui de educadores de pares que eram na comunidade as pessoas que prestavam palestras, mas houve um fracasso da organização em si. E com a fraca dessa atividade em relação a comunidade, não existe uma boa adesão, porque nós sabiamos os testados da comunidade, fazíamos dar continuidade e seguimento, mas agora não estamos a receber. Temos muitos educadores que não são muito sérios para atividade na comunidade. Falta um pouco de informação e se não trabalhamos com a liderança comunitária, nossos esforços são reduzidos.

\section{DISCUSSÃO}

As ideias centrais (IC) apresentaram fatores semelhantes aos que foram descritos na literatura. Em revisão de literatura, Santos et al. (2020) afirmam que há diversas barreiras para a adesão e que as mesmas estão diratamente relacionadas os contexto sócio-econômico. Os autores destacam que as limitações financeiras, o medo da descoberta do diagnóstico, esquecimento, ausência de compreensão dos benefícios do tratamento, dificuldades de acesso ao tratamento, reações adversas à medicação, escolaridade, ausência de apoio familiar e social são as principais dificuldades enfrentadas pelas PVHA.

Os profissionais entrevistados demonstram conhecer os meios pelos quais é possível ter acesso ao paciente que descontinuou o tratamento, visando retorno à unidade de saúde, o que impacta nos índices de adesão. $\mathrm{O}$ encontro com os pacientes, seja na unidade de saúde, seja por meio das visitas domiciliares, são oportunidades para troca de informações e esclarecimentos. A escassez de informações sobre o tratamento antirretroviral, inclusive, já havia sido apontada por Souza et al. (2019) como um fator que impacta negativamente a desejada adesão. Do mesmo modo, como defendem Guambe et al. (2019), é preciso assegurar que a informação seja capaz de alcançar o alvo com algum efeito, o que também pode requerer o bom uso dos dispositivos de informação em saúde.

A IC1 trata da perspectiva dos profissionais sobre o desafio da adesão com relação à ingestão dos medicamentos, pois muitos pacientes deixam de fazer uso dos mesmos em virtude de seus efeitos colaterais. É possível notar que há uma relação entre a IC1 e IC5, sendo que a última ideia central diz respeito especificamente à queixa sobre a falta de alimentação e sua influência sobre a toma dos medicamentos. Observa-se, por meio do depoimento dos profissionais, que os pacientes associam a falta de alimentação aos efeitos colaterais dos remédios como causas de se sentirem mais fracos fisicamente, o que acaba fazendo com que não utilizem o medicamento tal como fora recomendado. Cabe ressaltar que no início da política de oferta de TARV em Moçambique era comum receber, durante os aconselhamentos, orientação sobre a necessidade de prover melhorias na qualidade da alimentação para garantir maior sucesso no uso da medicação antirretroviral.

No estudo de Polejack (2007), os participantes relataram que a falta de condições de garantir alimentação adequada pode ser uma das causas do abandono do tratamento. Como as informações recebidas no momento do aconselhamento reforçam a importância de se realizar uma boa alimentação para um uso adequado do TARV, somado à crença de que as medicações provocam efeitos intensos no organismo, muitos desistem de usá-las tal como fora recomendado em virtude do receio em relação à intensidade dos efeitos adversos que o uso dos medicamentos sem o provimento de um padrão alimentar reforçado pode provocar. A autora destaca, ainda, que os participantes relataram aumento do apetite após início do tratamento e, em um contexto de vulnerabilidade sócio-económica e falta de alimentos, essa pode ser uma importante barreira para a adesão, uma vez que conflitos familiares podem ser gerados em virtude da carência de comida que satisfaça a todos os membros da família.

Ainda sobre o uso dos medicamentos, um outro fator em destaque é a dificuldade de acesso às Unidades de Saúde (US), apontado em IC5. Muitos pacientes não têm condições financeiras para arcar com os custos do transporte, o que é necessário para a retirada dos medicamentos na US, portanto, acabam não indo e, consequentemente, abandonam o tratamento. Nesse contexto, é possível notar que a barreira socioeconômica pode gerar muitas dificuldades para que os pacientes possam aderir ao TARV. Para Vieira et al. (2014), as pessoas vivendo com HIV/aids ainda enfrentam as barreiras ocasionadas pela falta de programas de assistência 
social que garanta direitos básicos como alimentação, habitação e transporte para aqueles que não têm condições de se inserir no mercado de trabalho em função da doença e do estigma que lhe é direcionado, já que, desde que surgiu, a aids disseminou rótulos estigmatizantes aos portadores de HIV (Machado et al., 2006).

Em face disso, estudos realizados por Pires et al. (2018) e Souza et al. (2019) apontam que problemas relacionados à insegurança alimentar e à baixa acessibilidade aos cuidados de saúde primário estão entre os determinantes de abandono do TARV. Adicionalmente, a insegurança alimentar é apresentada como um fator de risco e vulnerabilidade dos indivíduos, a qual pode estar relacionada com a incapacidade de conseguirem produzir ou comprar alimentos em quantidade suficiente (MISAU, 2015b). Tais aspectos chamam a atenção para a necessidade dos governos investirem em políticas sociais baseadas no princípio da equidade e no direito ao acesso à saúde, aliadas a ações de seguridade social e incetivo a projetos de geração de redimentos para ampliar o acesso da população à alimentação, além da redução das iniquidades.

As IC2 + IC6 referem-se aos recursos humanos, espaço físico e questões administrativas da US. Conclui-se, a partir do relato dos profissionais, que não há quantidade de clínicos suficiente para realizar o atendimento das pessoas vivendo com HIV. Assim, a demanda de pacientes é maior que o número de profissionais disponíveis na US para atendê-los, a considerar que os clínicos atendem outras demandas que não aquelas relacionadas ao HIV. Além disso, a IC2 denota que não há espaço suficiente para os atendimentos e acabam tendo que compartilhar salas. O serviço de TARV e de aconselhamento psicossocial acontecem na mesma sala e os atendimentos e procediemntos têm que ser realizados em um tempo exíguo, o que afeta a qualidade do aconselhamento. Ademais, é possível observar em IC6 que isso acarreta muita demora nos atendimentos, o que frustra os pacientes, pois chegam cedo à US e ficam esperando por longas horas nas filas. Acresça-se a isso o fato de terem que passar por várias filas diferentes, o que geral desestímulo e acaba fazendo com que desistam do tratamento.

Moçambique é visto como um dos países mais afetados com a falta de recursos humanos em saúde e isso tem gerado impactos negativos para os esforços de expansão da TARV, bem como, do Aconselhamento e testagem em saúde (ATS) e prevenção da transmissão vertical (MISAU, 2015b). Tal situação desencadeia uma série de problemas para a realização de um atendimento adequado e eficaz. Nesse sentido, o contexto organizacional e social são fatores que influenciam a adesão, já que acessar os serviços de saúde e sua estrutura impacta diretamente no tratamento. Países com recursos limitados apresentam maior dificuldade de investimento em infra-estrutura e pessoal, impactando na qualidade dos serviços oferecidos (Fonseca \& Corbo 2007; MISAU, 2018; Vieira et al., 2014). Tal aspecto realça a necessidade de que sejam elaboradas estratégias como task-shifting e envolvimento comunitário para ampliar a possibildiade de resposta e fortalecer as estratégias de apoio à adesão na comunidade. Moçambique tem desenvolvido algumas delas, como os Grupos de Apoio e Adesao Comuntária (GAAC), o investimento na capacitação de conselheiros leigos e educadores de pares, bem como a oferta de testagem na comunidade (ATSC) em parceria com organizações não-governamentais (MISAU, 2015b, 2015c; Okamura, 2016; Pires et al., 2018).

É plausível ressaltar que a vergonha e o medo de ter sua soropositividade revelada são razões que levam pacientes a não retornarem à US após realizado o primeiro aconselhamento da APSS, já que não é incomum que o paciente mude de endereço e não avise, além de fornecer endereços e números de telefone inexistentes no momento do cadastro (IC3). Os profissionais de saúde se queixam dos pacientes que já testaram, mas que, em virtude da descrença em relação ao resultado do teste, acabam se testando novamente para o HIV em outro distrito. Segundo os profissionais, quando isso ocorre e o diagnóstico é novamente confirmado, muitos pacientes abandonam o tratamento, o que demonstra que o aconselhamento inicial não surtiu os efeitos esperados. Tais comportamentos podem estar relacionados aos problemas relacionados ao estigma e discriminação direcionados à pessoa com HIV, conforme mencionado por Machado et al. (2006) e Pires et al. (2018), já que ser visto na US revela forçadamente sua situação de saúde (IC4+IC7).

A IC4 e IC7 relacionam-se entre si, uma vez que versam sobre a questão da não revelação do diagnóstico e da discriminação. Quando o estado de saúde não é de conhecimento do parceiro e familiares, a adesão ao TARV é dificultada, pois a pessoa somente irá tomar os medicamentos quando ninguém estiver presenciando. Além disso, muitos não querem fazer o tratamento perto de casa para não serem vistos, pois há discriminação até mesmo dentro de suas próprias casas, o que também impacta negativamente nos índices de adesão. Sobre isso, Taela (2004) ressalta que, por ainda se tratar de uma doença estigmatizada, a vivência das pessoas que vivem com o HIV é diferente das vivências de pessoas acometidas por outras doenças, uma vez que as primeiras tendem a ser rejeitadas e evitadas em sociedades onde prevaleçam o estigma e a discriminação. A pressão social pode gerar maior dificuldade em relação a revelação do diagnóstico e resultar em baixo acesso ao apoio social (Polejack, 2007). Ainda segundo a autora, a dificuldade em revelar o diagnóstico para o parceiro está ligada ao medo de sofrer rejeição por parte deste, da sociedade e da família. Diante disso, o estigma e a discriminação se mostram como grandes dificultadores da adesão ao TARV, uma vez que os pacientes deixam de iniciar e/ou seguir no tratamento para não sofrerem tais consequências.

A melhoria de serviços de apoio ao TARV requer a visão de que sujeitos e famílias são sistemas a serem compreendidos, além do reconhecimento dos aparelhos 
sociais como contribuidores para o tratamento e possíveis instrumentos para a atuação de profissionais (Leadebal et al., 2016). O estímulo ao diálogo coletivo cabe ao profissional, o que pode ser feito por meio do desenvolvimento de estratégias de educação em saúde com foco na integralidade do cuidado (Durgante et al., 2015). Nesse sentido, devem ser abertos espaços de promoção de saúde para além do cuidado individual, com possibilidade de expressão emocional e construção de projetos de vida associados à adesão ao TARV (Levandowski et al., 2014).

Outro fator relevante apontado pelos profissionais é a sorodiferença ou sorodiscordância (quando um dos membros do casal é positivo para o HIV e o outro não) como um dos grandes desafios, principalmente, nas cidades quando comparadas às zonas rurais (IC4). Sobre essa ideia, é possível observar uma questão relacionada ao gênero, diante do relato de que algumas mulheres são impedidas, pelo cônjuge, de prosseguir no tratamento e, até mesmo, de que sentem receio de serem expulsas de casa.

Fatores como a desigualdade de gênero, estigmatização e discriminação estão presentes na vida de mulheres com HIV, o que não deixa de ocorrer na vivência dos homens soropositivos, mas de modos diferentes, de acordo com os papéis que lhes são socialmente atribuídos. Segundo o estudo realizado pelos autores em Moçambique, as mulheres são vítimas de julgamento moral e culpabilização da sociedade pela doença e, consequentemente, seu acesso a espaços e direitos se torna limitado. A partir disso pode se iniciar um processo de perda da autonomia por não se reconhecerem mais como cidadãs dotadas de direitos e pertencentes a uma comunidade. É importante colocar também que, frequentemente, a própria equipe de saúde reforça em suas práticas o estigma sofrido por pessoas soropositivas e, que para que isso deixe de acontecer, deve haver um esforço coletivo de preparação e conscientização acerca do estigma (Andrade \& Iriart, 2015).

Corroborando com a importância de se considerar as questões de gênero na relação entre pessoas vivendo com HIV, as crenças e práticas culturais sustentam as desigualdades de gênero, colocam a mulher em uma posição de submissão na sociedade e aumentam sua vulnerabilidade à infecção (MISAU, 2015b). Além disso, "a forte desigualdade de gênero em Moçambique faz com que as mulheres sejam frequentemente culpabilizadas pela infecção com o HIV" (Andrade \& Iriart, 2015, p. 568). Os autores afirmam, ainda, que as mulheres são reticentes em revelar seu diagnóstico por receio de suscitar questionamentos e suspeitas de infidelidade, pois há casos em que os maridos que desconhecem seu próprio estado sorológico culpabilizam e discriminam suas esposas, atribuindo a elas a responsabilidade pela contaminação. Sobre esse aspecto, Matavel (2019) destaca que alguns elementos que impulsionam a vulnerabilidade individual, como as práticas sexuais com múltiplos parceiros sexuais, relações sexuais desprotegidas, situações de violência, algumas práticas culturais (como a Kutchinga) e o tratamento por curandeiros parecem aumentar ainda mais a vulnerabilidade social das mulheres em Moçambique, assim como ampliam as desigualdades de gênero, violência, o estigma e a discriminação.

Os aspectos relacionados à tradição e à busca pelo tratamento tradicional também foram apontados como barreiras, bem como a falta de informação no âmbito da comunidade, a qual também está entre os fatores que dificultam a adesão (IC8+IC9), o que se configura como um desafio, pois os praticantes da medicina tradicional baseiam suas orientações na compreensão do sistema de crenças culturais relacionando às infecções de transmissão sexual a questões espirituais (MISAU, 2015a). Importante destacar que:

todas as pessoas terão uma forma de explicar o seu problema de saúde. Acontece, porém, que essas explicações podem ser diferentes daquelas apresentadas pelos profissionais de saúde e pela medicina. Quando isto acontece, chegam a ocorrer conflitos entre aquilo que é o modo de explicar apresentado pelos profissionais de saúde e a forma pela qual os utentes e comunidades no geral explicam esse mesmo problema. (MISAU, 2010, p. 14)

Para haver alguma mudança, é necessário levar em consideração as crenças que constituem a cultura local. Dependendo da forma como a cultura se expressa em determinadas comunidades, isso pode acontecer com maior ou menor dificuldade (MISAU, 2010). Depreendese, portanto, que existem aspectos da doença fortemente atrelados às crenças dos pacientes e à cultura de onde vivem, assim como o modo como a doença deve ser tratada difere entre as pessoas, gerando conflitos entre profissionais e pacientes. É fundamental que haja um trabalho coordenado entre o sistema de saúde e os praticantes da medicina tradicional, para sejam definidas estratégias que respeitem a cultura e reforcem o diálogo com a população, sem deixar de oferecer informações sobre medidas de prevenção e a importância dos medicamentos antirretrovirais.

\section{CONSIDERAÇÕES FINAIS}

O presente trabalho possibilitou uma melhor compreensão sobre fatores que dificultam o processo de adesão ao TARV a partir da perspectiva dos profissionais de saúde. Foi possível compreender o caráter multideterminado da adesão, levando em conta os argumentos apresentados pelos profissionais no âmbito da pesquisa. Notou-se que a adesão envolve questões 
econômicas, sociais e culturais, comportamentos individuais e coletivos e até mesmo a própria estrutura oferecida pelo sistema de saúde.

A cultura e a forma como as pessoas lidam com o HIV exercem grande influência sobre o processo de adesão, uma vez que a doença é fortemente estigmatizada em Moçambique. É possível observar que o estigma e a discriminação geram uma série de problemas adicionais já que lançam mão e inúmeros artifícios para não ter sua situação de saúde revelada. Com isso, muitos abandonam o tratamento, principalmente pelo fato de se recusarem a realizar o tratamento em uma unidade próxima às suas residências, visando ao anonimato de sua condição virológica.

Este artigo buscou esclarecer a percepção dos profissionais da área da saúde em Moçambique sobre a adesão ao tratamento antirretroviral. Acredita-se que os resultados encontrados coroboram para o planejamento e desenvolvimento de novas ações e pesquisas na área.

Vale ressaltar que o estudo enfrentou algumas limitações, como a não realização de entrevistas em todas as províncias do país. Tampouco se especificou qual era a área de atuação de cada profissional de saúde entrevistado, o que impediu uma comparação das respostas intragrupos. Diante disso, sugere-se que sejam realizadas novas pesquisas com um número maior de participantes sobre os temas abordados por este estudo, possibilitando, assim, um maior aprofundamento sobre os mesmos.

$\mathrm{O}$ trabalho realizado em parceria pelos pesquisadores da Universidade de Brasília (UnB) e da instituição moçambicana Universidade Eduardo Mondlane (UEM), localizada em Maputo, mostrou-se ferramenta eficaz para produzir resultados importantes no combate da epidemia do HIV/aids e na oferta de informações culturalmente relevantes para o fortalecimento de políticas públicas alinhadas com as necessidades locais. Ademais, a troca de experiências favorece a integração entre os países do sul do globo, o que contribui para diminuir a lacuna histórica que há entre a ciência que se produz nos países desenvolvidos (nem sempre sensíveis às diferenças culturais), em detrimento daquela que tem sido praticada nos países pobres ou em desenvolvimento. Cabe ressaltar que a inserção dos pesquisadores nas culturas locais onde as pesquisas são conduzidas é um ponto alto do estudo. Sugere-se que mais pesquisas sejam desenvolvidas a partir dessa perspectiva de intercâmbio centífico e cultural.
As barreiras para a adesão são diversas, podendo-se destacar as limitações financeiras, o medo da descoberta do diagnóstico, a ausência de compreensão dos benefícios do tratamento e as dificuldades de acesso ao mesmo temas especialmente relevantes para os contextos dos países em desenvolvimento. Outros fatores que interferem negativamente na adesão são as reações adversas à medicação e a ausência de apoio familiar e social. Como nas três regiões do país a dificuldade de adesão também se mostrou relacionada com a forma de organização dos serviços de saúde, especificamente em relação à falta de recursos humanos e a problemas na organização das US, explicita-se a necessidade de se criarem condições para monitoramento e avaliação da adesão de forma rotineira.

A questão de gênero continua sendo central para a resposta à epidemia do HIV em Moçambique pois, para além das questões de igualdade no seio familiar, as mesmas ferem o direito ao acesso à saúde. Isso demonstra que o setor saúde para o enfrentamento do HIV/aids no país também deve contar com a participação de outros órgãos públicos nacionais, visto que há assuntos que interferem nos cuidados de saúde, mas que são temas de atuação de outros setores. Aspectos sociais como a fome, dificuldades financeiras, problemas com transporte, entre outros, impactam na qualidade das ações oferecidas e, adicionalmente, nos resultados esperados do combate à epidemia, principalmente ao se considerar os determinantes sociais da saúde. Em especial em relação à fome, primeiramente há de se assegurar a disponibilidade básica de alimentos para que, futuramente, possam ser envidados esforços mais específicos relacionados a esse aspecto, como é o caso da manutenção de práticas alimentares saudáveis, já que esse é um dos comportamentos de saúde que se relacionam a uma adequada adesão, em virtude dos efeitos do TARV.

O estudo apontou uma radiografia da visão dos profissionais de saúde que atuam em Moçambique sobre os fatores que interferem na adesão de pacientes HIV+ ao tratamento a que têm acesso. Espera-se que as informações aqui disponibilizadas possam suscitar tomadas de decisão por parte dos gestores responsáveis pela área no país. A partir do conhecimento desses resultados, acredita-se que novos estudos venham a ser desenvolvidos junto aos profissionais de saúde e demais atores em saúde, permitindo, assim, que sejam realizadas ações pontuais que garantam o aumento da adesão por parte dos pacientes.

\section{REFERÊNCIAS}

Agostini, R., Rocha, F., Melo, E., \& Maksud, I. (2019). A resposta brasileira à epidemia de HIV/AIDS em tempos de crise. Ciência \& Saúde Coletiva, 24(12), 4599-4604. https://doi. org/10.1590/1413-812320182412.25542019

Andrade, R. G., \& Iriart, J. A. B. (2015). Estigma e discriminação: Experiências de mulheres HIV positivas nos bairros populares de Maputo, Moçambique. Caderno Saúde Pública, 31(3), 565573. https://doi.org/10.1590/0102-311x00019214

Baggaley, R. F., \& Hollingsworth, T. D. (2020). How universal does universal test and treat have to be? The Lancet, 7, 306-308. https://doi.org/10.1016/S2352-3018(20)30031-X

Brambatti, L. P., \& Carvalho, W. M. E. S. (2005). A adesão ao tratamento em pessoas vivendo com HIV/Sida: Barreiras e 
possibilidades. Revista de Saúde do Distrito Federal, 16(3/4), 7-21.

Brasil (2008). Manual de Adesão do Tratamento para pessoas vivendo com HIV e aids. Série A. Normas e Manuais Técnicos, N. 84. Ministério da Saúde, Secretaria de Vigilância à Saúde, Programa Nacional de DST e Aids. http://bvsms.saude.gov.br/ bvs/publicacoes/manual_adesao tratamento_hiv.pdf

Chesney, M. A., Morin, M., \& Sherr, L. (2000). Adherence to HIV combination therapy. Social Science and Medicine, 50(11), 1599-1605. http://atar-vih.wdfiles.com/local--files/biblio/ chesney_adherence $\% 20$ to $\% 20$ HIV\%20therapy_soc\%20 sci\%20med.pdf

Costa, M. M. R., Vilaça, D. H. V., Pereira, A. M. C., Tavares, A. V. S., Menezes, H. L., Queiroz, W. S., Maciel, R. F. M., Torquato, K. D. S., \& Martins, A. G. S. (2019). Qualidade de vida de indivíduos com HIV: Revisão integrativa. Brazilian Journal of Health Review, 2(3), 1833-1842. http://www.brjd.com.br/ index.php/BJHR/article/view/1490/1566

Coutinho, M. F. C., O’Dwuer, G., \& Frossard, V. (2018). Tratamento antirretroviral: Adesão e a influência da depressão em usuários com HIV/Aids atendidos na atenção primária. Saúde Debate, 42(116), 148-161. https://doi.org/10.1590/01031104201811612

Durgante, V., Budó, M., \& Guido, L. (2015). Mulheres com AIDS: Disponibilidade e satisfação do suporte social. Ciência, Cuidado e Saúde, 14(1), 814-821. https://doi.org/10.4025/ cienccuidsaude.v14i1.19934

Fedatto, M. S. (2017). Epidemia da AIDS e a Sociedade Moçambicana de Medicamentos: Análise da cooperação brasileira. Ciência e Saúde Coletiva, 22(7), 2295-2304. https:// doi.org/10.1590/1413-81232017227.03892017.

Fonseca, A. F., \& Corbo, A. D. (2007). O território e o processo saúde-doença. EPSJV/ Fiocruz. https://www.arca.fiocruz. br/bitstream/icict/26572/2/Livro\%20EPSJV\%20005909.pdf

Guambe, A. J., Gastalho, P. P. G., Polejack, L., \& Machado, A. C. (2019). Informação, educação e comunicação em saúde para a população de homens que fazem sexo com homens em Moçambique. Sexualidade e Política, 1(1), 275-292. https://revista.todxs.org/wp-content/uploads/2019/08/13Informa $\% \mathrm{C} 3 \% \mathrm{~A} 7 \% \mathrm{C} 3 \% \mathrm{~A} 30-$ Educa $\% \mathrm{C} 3 \% \mathrm{~A} 7 \% \mathrm{C} 3 \% \mathrm{~A} 3 \mathrm{o}-\mathrm{e}-$ Comunica\%C3\%A7\%C3\%A3o-em-sa\%C3\%BAde.pdf

Leadebal, O., Medeiros, L., Morais, K., Nascimento, J., Monroe, A., \& Nogueira, J. (2016). Manejo de risco na gestão do cuidado especializado a pessoas vivendo com AIDS. Revista da Escola Enfermagem da USP, 50(5), 840-847. https://doi.org/10.1590/ s0080-623420160000600018

Lefèvre, F.; \& Lefèvre, A. M. C. (2005). O discurso do sujeito coletivo: Um novo enfoque em pesquisa qualitativa ( $2^{\mathrm{a}}$. ed). Educs.

Levandowski, D. C., Pereira, M. D., Dores, S. D., Ritt, G. C., Schuck, L. M., \& Sanches, I. R. (2014). Vivência da gravidez em situação de seropositividade para HIV: Revisão da literatura brasileira. Análise Psicológica, 32(3), 259-277. https://doi. org/10.14417/ap.575

Machado. A. C. A., Raggio, A. M. B., Carvalho, L. V., \& Garrafa, V. (2006). Estigma, lipodistrofia e HIV/AIDS: Estudo bioético. In V. Garrafa \& J. Cordón (Eds.). Pesquisas em Bioética no Brasil de Hoje (pp. 63-84), Gaia.

Matavel, O. A. (2019). Vulnerabilidades das mulheres, violência de gênero e a infecção pelo VIH/SIDA na cidade de Maputo, Moçambique [Tese de doutorado]. Repositório da Universidade Nova. https://run.unl.pt/bitstream/10362/73717/1/ Tese Vulnerabilidades $\% 20$ das $\% 20$ mulheres $\% 2 \mathrm{C} \% 20$ viol $\%$ C3\%AAncia\%20de\%20g\%C3\%A9nero\%20e\%20 infe $\% \mathrm{C} 3 \% \mathrm{~A} 7 \% \mathrm{C} 3 \% \mathrm{~A} 3 \mathrm{o} \% 20$ pelo $\% 20$ VIHSIDA $\% 20 \mathrm{em} \% 20$ Mo\%C3\%A7ambique_05_06_2019.pdf

Medeiros, R. C. R. C., Medeiros, J. A., Silva, T. A. L., Andrade, R. D., Medeiros, D. C., Araújo, J. S., Oliveira, A. M. G., Costa,
M. A. A., Cabral, B. G. A. T., \& Dantas, P. M. S. (2017). Qualidade de vida, fatores socioeconômicos e clínicos e prática de exercício físico em pessoas vivendo com HIV/aids. Revista de Saúde Pública, 2017, 51-66. https://doi.org/10.1590/S15188787.2017051006266

Ministério da Saúde de Moçambique. (2010). Contribuição da antropologia para a saúde pública: Um enfoque nos programas de maternidade segura, HIV e SIDA [Manual de Formação]. https://www.medicusmundi.es/storage/resources/ publications/571e37988275e.pdf

Ministério da Saúde de Moçambique. (2015a). Relatório Anual 2014. Relatório Anual das Actividades Relacionadas ao HIV/SIDA. Ministério da Saúde, Serviço Nacional de Saúde. http://www.misau.gov.mz/index.php/relatoriosanuais?download=87:relatorio-anual-hiv-2014-final

Ministério da Saúde de Moçambique. (2015b). Directriz Nacional de Melhoria de Qualidade dos Cuidados e Tratamento para $H I V$ e SIDA. Ministério da Saúde, Direcção Nacional de Assistência Médica, Programa Nacional de Controle de ITS, HIV e SIDA. http://www.misau.gov.mz/index.php/directrizesnacionais?download=74:directriz-nacional-de-melhoria-dequalidade-dos-cuidados-e-tratamento-para-hiv-e-sida-2015

Ministério da Saúde de Moçambique. (2015c). Estratégia de Grupos de Apoio e Adesão Comunitária. Maputo, Ministério da Saúde, Direcção Nacional de Assistência Médica, Programa Nacional de Controle de ITS, HIV e SIDA. http://www.misau.gov.mz/ index.php/directrizes-nacionais?download=77:estrategia-degrupos-de-apoio-e-adesao-comunitaria-gaac

Ministério da Saúde de Moçambique. (2019). Inquérito de Indicadores de Imunização, Malária e HIV/SIDA em Moçambique (IMASIDA) 2015. Relatório Suplementar Incorporado os Resultados de Biomarcadores de Antiretrovirais. Ministério da Saúde \& Instituto Nacional de Estatística (INE). https://www.dhsprogram.com/pubs/pdf/AIS12/AIS12_SP.pdf

Mitano, F., Ventura, C. A. A., \& Palha, P. F. (2016). Saúde e desenvolvimento na África subsaariana: Uma reflexão com enfoque em Moçambique. Physis, 26(3), 901-915. https://doi. org/10.1590/S0103-73312016000300010

Monié, F. (2020). A África subsaariana diante da pandemia de coronavírus: Difusão espacial, impactos e desafios. Espaço e Economia, 18, 1-26. https://doi.org/10.4000/ espacoeconomia.13629

Okamura, M. (2016). Avaliação de um Projeto de Fortalecimento das Capacidades para Resposta ao HIV: Estudo de Caso na Província de Gaza-Moçambique [Tese de doutorado]. Repositório da Universidade Nova. https://run.unl.pt/ bitstream/10362/20096/1/170112_Tese_MieOkamura_final. pdf

Pires, P. N., Marega, A., \& Creagh, J. M. (2018). Terapia antirretroviral: Investigação de implementação nos cuidados de saúde primários, Nampula, Moçambique. Revista Portuguesa de Medicina Geral e Familiar, 34(5), 274-286. https://doi. org/10.32385/rpmgf.v34i5.12312

Polejack, L. (2007). Compartilhando olhares, diálogos e caminhos: adesão ao tratamento Anti-retroviral e qualidade de vida em pessoas vivendo com HIV/AIDS em Maputo, Moçambique [Tese de doutorado]. Repositório UnB. http://repositorio.unb. br/bitstream/10482/8307/1/2007_LarissaPolejackBrambatti. pdf

Polejack, L., \& Seidl, E. M. F. (2010). Monitoramento e avaliação da adesão ao tratamento antirretroviral para HIV/AIDS: Desafios e possibilidades. Ciência \& Saúde Coletiva, 15(Suppl. 1), 12011208. https://doi.org/10.1590/S1413-81232010000700029

Programa Conjunto das Nações Unidas sobre HIV/AIDS. (2014). Declaração de Paris - Acabar com a epidemia da Aids: Cidades acelerando a resposta para alcançar as metas 9090-90 até 2020. https://www.unaids.org/sites/default/files/ media_asset/2019-global-AIDS-update_en.pdf 
Programa Conjunto das Nações Unidas sobre HIV/AIDS. (2019a). Global AIDS Update: communities at the centre. Defending rights, breaking barriers, reaching people with HIV services. https://www.unaids.org/sites/default/files/media_asset/2019global-AIDS-update en.pdf

Programa Conjunto das Nações Unidas sobre HIV/aids. (2019b). UNAIDS Data 2019. https://www.unaids.org/sites/default/files/ media asset/2019-UNAIDS-data en.pdf

Santos, K. R. F. N., Carneiro, W. S., Vieira, A. S., Souza, M. B., \& Gonçalves, C. F. G. (2020). Fatores que interferem na adesão e permanência da terapia antirretroviral. Brazilian Journal of Health Review, 3(2), 3037-3043. https://doi.org/10.34119/ bjhrv3n2-143

Souza, H. C., Mota, M. R., Alves, A. R., Lima, F. D., Chaves, S. N., Dantas, R. A. E., Abdelmur, S. B. M., \& Mota, A. P. V. S.
(2019). Análise da adesão ao tratamento com antirretrovirais em pacientes com HIV/AIDS. Revista Brasileira de Enfermagem, 72(5), 1361-1369. https://doi.org/10.1590/00347167-2018-0115

Taela, K. (2004). Análise da documentação sobre o estigma e a discriminação relacionados com o HIV/SIDA em Moçambique. Maputo, N'weti Comunicação para Saúde. https://www.iese. ac.mz/ ieseacmz/lib/PPI/IESE-PPI/pastas/governacao/saude/ artigos_cientificos_imprensa/estigma_discriminacao.pdf

Vieira, A. C. S., Rocha, M. S. G., Head, J. F., \& Casimiro, I. M. A. P. C. (2014). A epidemia de HIV/AIDS e a ação do Estado: Diferenças entre Brasil, África do Sul e Moçambique. Katálysis, 17(2), 196-206. https://doi.org/10.1590/S141449802014000200005 